\title{
LES JORNADES D'ESTUDI CATALUNYA-EUSKADI *
}

\author{
Faustino Miguélez \\ (Universitat Autònoma de Barcelona)
}

Les Tornades d'Estudi Catalunya-Euskadi: societat i politica, que tingueren 110 a Sitges del 28 al 30 de setembre de 1983, organitzades pels departaments de Sociologia de les Universitats Autònoma de Barcelona i del País Basc, no són la primera experiència d'aquesta mena. S'han celebrat en els darrers anys seminaris i jornades d'intercanvi entre diverses universitats espanyoles, i a la mateixa Universitat Autònoma de Batcelona n'hi ha hagut amb presència d'universitaris bascs $i$ asturians. Tot $i$ que en el passat també s'havien celebrat aitals trobades, potser ara es tracti de quelcom diferent, d'una resposta que la Universitat dóna a les noves exigències de la societat.

Ben segur que totes aquestes iniciatives responen a una doble necessitat. D'una banda a la necessitat de conèixer la riquesa específica que en el camp de les idees, de la cultura i de la recerca contenen totes i cadascuna de les nacions i regions d'Espanya, sovint ignorades sota una pretesa uniformitat que en temps passats ha estat estirilitzant o bé ha degenetat en repressió. I de l'altra, a la necessitat d'alliberat-se de possibjes visions localistes o «provincialistes» en el sentit mesquí d'aquests termes. El nou context polític podria comportar el perill de tancar-se i de no veure més enllà de les fronteres de la pròpia "comunitat autònoma» amb greu perjudici per a l'estudi que, si es vol crític i engrescador, per força cal que sigui d'abast universal.

* Traducció d'Antoni Estradé. 


\section{EUSKADI.CATALUNYA: SEMBLANCES I DIFERENCIES}

Quan vàrem encetar els contactes per a la celebració de les Jornades de Sitges ho fèiem des d'una imatge de Catalunya i d'Euskadi semblant a la de la majoria de ciutadans d'aquest país. Pel que fa al desenvolupament econòmic creiem que l'una i l'altra s'assemblen força, i se situen mal. grat l'expansió econòmica general a l'Espanya dels anys seixanta al capdavant de les diverses nacions $\mathrm{i}$ regions - si se'ns permet aquesta expressió desenvolupista només en termes descriptius. Però pel que fa a la política houn hi pot veure diferències importants encara que, també ací, un element comú hi faci un paper determinant: el problema nacional. Institucionalment aquestes diferències hi són molt clarament, per exemple en el sistema de partits $i$ en I'organització del moviment obrer. Si ens allunyem de les institucions les diferències són encara més grans, caracteritzades de manera particular pel terrorisme $i$ la violència en el cas d'Euskadi, $i$ per una pregona apatia política, que alguns poden interpretar com a simple delegacio política, en el cas de Catalunya.

Atès això, la qüestió fonamental que volíem posar-nos des de la Sociologia era: Quins trets característics ha tingut i està tenint el procés de modernització a Euskadi i a Catalunya? En la resposta a aquesta pregunta ens semblava que calia defugir el determinisme d'alguns indicadors (taxa d'ocupació, renda per càpita, producte industrial) la importància dels quals, com és obvi, no neguem, així com la idea que el desenvolupannent dels anys seixanta, considerat de manera abstracta, anava esborrant les velles diferències existents entre les distintes zones d'Espanya. Així doncs, l'objectiu del debat calia que fos doble: en primer lloc, analitzar les transformacions que algunes característiques estructurals havien patit en una i altra nació; en segon lloc avaluar el pes de factors culturals, ideològics, polítics, de consciència collectiva, $i$ fins $i$ tot psicològics en l'anomenat procés de modernització. Aquestes primeres jornades eren centrades més aviat sobre el primer tipus d'indicadors i si no es varen discutir més els segons fou per una pura opció metodològica.

Veurem, doncs, en aquesta breu introducció, algunes qüestions importants que poden animar a la lectura de les ponències que tot seguit trobarem.

Catalunya i Euskadi han tingut el seu màxim ritme d'expansió demogràfica en el període 1950-1975. Catalunya ha crescut durant aquests anys un $75 \%$, Euskadi un $77 \%$. En tots dos casos hi ha un element determinant d'un creixement tan sobtat: la immigtació. Tanmateix, el nostre present no és tan sols fruit d'aquest passat recent, sinó d'una història més llarga i, si així és, hauríem d'eixamplar el matc explicatiu. Si ho fem, 
podrem veure elements nous i diferenciadors. A la primera dècada del segle, Euskadi perd població per emigració (-31.962) i en les succesives, fins a la de 1951-1960, el seu saldo positiu mai no ultrapassa les 9.000 persones; el gtan creixement és el de les dècades de 1950 (131.727) i 1960 (274.323). Per contra, Catalunya té sempre saldo positiu, si bé amb variacions interiors intercomarcals, des de començament de segle, molt impot. tants ja des de la segona dècada (224.291); i si bé és cert que la dels seixan. ta és la «dècada immigratòria» per antonomàsia (719.877) la dels cinquanta no li va massa al dartera (439.887) i ni tan sols la dels vint (321.995). Dit amb altres mots, el creixenent accelezat per immigració massiva prové, a Catalunya, de molt més antic, com de bastant més enilà es remunta la industrialització mateixa. Mentre que a Euskadi, la industrialització generalitzada és posterior a la guerra civil, si bé alguns dels seus eixos importants, en concret la siderometallúrgia i la gran banca, provenen ja de finals del segle $\mathrm{xIx} i$ de principis del $\mathrm{xx}$ respectivament.

D'aquesta manera, ha estat molt diferent el procés en el qual s'han produit la immigració i el corresponent creixement demogràfic, així com la incidència d'aquests factors en la conversió de Catalunya i Euskadi en societats urbanes i industrials. A tot això, hi podríem afegir el major nombre dels treballadors ocupats a la gran empresa a Euskadi, contrastant amb la consistència de la mitjana empresa a Catalunya. I un factor aparentment comú, l'empresa familiar; però potser fins i tot en aquest cas amb característiques prou diferenciades: a Catalunya va molt més lligada a la xarxa industrial general amb centre a Barcelona, mentre que a Euskadi gaudeix d'una més gran autonomia i d'una estructura més localista i més rural.

Aqquestes dissemblances estructurais a les quals ens referim a més d'alttes, han de tenir influència en la manera diversificada en què es dóna en un o altre país el procés d'«integració» dels immigants.

A Catalunya les grans onades immigratòries dels anys cinquanta i seixanta troben ja un conjunt important d'immigrants anteriors integrats a la classe treballadora catalana, que han participat en els principals esdeveniments político-socials dels país, des de començament de segle, com a co-protagonistes al costat dels catalans d'origen. En canvi, en ésser recents els corrents migratoris cap a Euskadi, la quiestió de lá integració s'ha plantejat, necessàriament, molt més vinculada als problemes polítics recents -els de la dictadura franquista i la democràcia.

En el model d'urbanització hi ha aiguna cosa en comú: la gran densitat i el creixement fora de mida, a borbollades, de les ciutats industrials d'Eus. kadi i de Catalunya. Crec, petò, que també hi ha un element cabdal de diferenciació: el model català és de centralització a l'entorn de Batcelona, fins al punt que en un $8 \%$ del tertitori s'hi troba concentrat el $80 \%$ de 
la població; i encata la resta, si més no per taons industrials, turistiques, de comunicacions, etc., té tendència a polaritzar-se a l'entorn del centre metropolità abans esmentat. L'urbanisme d'Euskadi podríem dir que és més policèntric, d'«àrea dispersa», com algun autor I'ba qualificat.

Aquesta diferència de models pot tenir consequèencies molt iraportants sobre l'estructura social en el seu conjunt, alguns dels quals ja es contemplaven a les Jornades de Sitges, mentre que d'altres caldrà que siguin aprofundits en properes refiexions: el model cultural centralitzat o descentra. litzat, els diferents usos socials del sòl, la distribució territorial dels diferents estrats socials - -per exemple a Barcelona ciutat viuen la major part dels professionals i dels polítics de Catalunya-, l'ensenyament, l'otganització de les forces socials (sindicats, empresaris, consumidors), la centralització política... Contraposat al centralisme polític i cultural batcelonès amb el qual es pot acabar veient tot Catalunya amb ets ulls de la metròpoli, tenim el policentrisme basc, que probablement dóna una més gran complexitat - $\mathrm{i}$ qui sap si riquesa - a les relacions socials i polítiques. Tots aquests elements es veuen infiuits per l'existència d'un o altre model que, al seu torn, no pot ser interpretat només en termes demogràfics, sinó que històricament té connotacions diferencials pel que fa a la cultura, la tradictó o la política.

Un altre aspecte important que cal tenir en compte és el relacionat amb l'estructura de l'ocupació. Sens dubte de cap mena, en compatació amb la testa d'Espanya, ens trobem amb la zona més capitalista o on el capitalisme és més avançat, considerant alhora Eusḱkadi i Catalunya. Les taxes de salarització, segons dades del 1970 , van més enllà del $80 \%$ de la població activa, els sectors d'empleats i tècnics assalariats - les «noves classes mitjanes», com han estat anomenades- són superiors amb escreix al conjunt d'Espanya. Però les diferències entre Euskadi i Catalunya no deixen d'ésser notables.

La diferència més rellevant és, potser, que Catalunya és encara més manual i menys tecnificada pel que fa a la seva estructura ocupacional, la qual cosa, com és lògic, incidejx sobre la configuració dels diferents grups socials respectius: la classe treballadora, les capes mitjanes i d'altres. Des de la perspectiva sociològica aquestes diferències tenen conseqüències que incideixen en d'altres temes tractats també a les Jornades de Sitges: el vot polític, Ia concepció de la identitat nacional, els nivells organitzatius i els trets característics de les organitzacions, la repercussió de la crisi, si bé tot això no es produeix, és clar, de manera mecànica. Les raons d'aitals diferències ocupacionals potser cal cercar-les en la diferent implantació de sectors econòmics més moderns, diferències en la dimensió de les empreses i d'altres. Sigui com sigui, hauríem de fer veure ben clar que aquestes dades sobre 
estructura ocupacional són prou indicatives del fet que no sempre és veritat que un país industrialitzat de fa més temps faci abans el pas cap una més gran tecnificació; ans al contrari, allò que sembla evident és que les formes de modernització industrial són diferents fins i tot dins d'un mateix país.

Ocupacions 1970

\begin{tabular}{|c|c|c|}
\hline & Euskadi & Catalunya \\
\hline 1. Manuals $\ldots \ldots \ldots \ldots \ldots$ & 47,2 & 52,69 \\
\hline 2. No manuals ............ & 42,8 & 37,42 \\
\hline 3. Agrícoles $\ldots \ldots \ldots \ldots \ldots$ & 10,0 & 8,31 \\
\hline
\end{tabular}

Dels debats sobre diversos elements d'estructura social catalana i basca sobresurten dues hipòtesis que $\mathrm{ja}$ foren discutides fins a un cert punt a Sitges, però que haurien de ser objecte d'un estudi específic i més aptofundit. Examinem-les breument.

La primeta fa referència a les característiques de la modernitat. Es podria assenyalar que Catalunya és una societat amb més grans influències urbanes $i$ industrials que es reflecteixen en taxes de natalitat més baixes, en una concepció més laica (funcional) de la família i més negociadora de les relacions laborals, socials i polítiques; amb una religió més concebuda en I'àrea privada. Euskadi podria veure's com una societat amb més influències rurals, comportaments de fecunditat menys restringits, unes rela. cions laborals més influides pel paternalisme - sobretot en les empreses petites de les zones rurals, no pas a les grans-m i relacions socials i politiques menys pactistes, amb una major projecció pública de la influència teligiosa...

Tots aquests supòsits, que en cap cas són valoratius, palesarien que les "vies de modernitzación són diverses de fet, que no es regeixen per un únic model $i$ que les diferències existents han de servir per a explicar-nos les característiques específiques que tenen les relacions socials en una societat determinada.

La segona hipòtesi faria referència al tema de la identitat nacional que, sens dubte, fa un paper important tant a Catalunya com a Euskadi, per part de quasi tots els subjectes socials i polítics. Ni allò que convencionalment qualifiquem com a dretes ni les esquerres mantenen discursos equiparables, ni les diverses organitzacions socials i polítiques, ni la 
societat en general. Hom pot pensar que la identitat pròpia és viscuda de maneta diferent. Sense voler establir-ho com a categoria analítica, gosaria indicar que la vivència de la identitat nacional a Euskadi té trets més aviat de grup primari, de vinculació amb la terra i els avantpassats, d'identificació amb grups de referència més primatis. Mentre que a Catalunya s'hi configuraria una vivència més laica de la identitat nacional, més centrada en la producció i la política. És clar que aquest és un tema de gran com. plexitat, però en el qual no ens hauria de fer por d'entrar, tot tractant d'esbrinar i separar els aspectes ideològics dels polítics, els psicològics dels econòmics $i$ analitzant quina influència tenen, en la identitat que es viu com a poble, factors com és ara la tradició, la teligió i d'altres.

Als estudiosos socials se'ns planteja, per tant, el repte d'anar desxifrant científicament, sense caure en xovinismes, la realitat social de l'Estat de les autonomies.

\section{LA PLURALITAT D'ESPANYA}

Una primera trobada sobre aquesta problemàtica calia, per força, que fos limitada i que contribuís més aviat a desvetllar preguntes que no pas a donar respostes o a extreure'n conclusions. Però de fet permet d'apuntat una conclusió: que fins i tot dins d'un mateix marc polític i d'un mateix sistema sòcio-econòmic les característiques que adquireixen els procesos de modernització $\mathrm{i}$ de canvi són diferents per a cada poble. Per diferències històriques $i$ actuals tenim a Espanya una pluralitat que fóra absurd d'ignorar.

Als científics socials pertoca de portar a terme l'anàlisi de les característiques pròpies de les nacions i regions d'Espanya. Aquesta tasca, petò, no pot fer-nos desentendre d'allò que està passant en el pia polític. Però també eis polítics l'ertatien si no fessin cas d'allò que es desprèn de l'anàlisi cien. tífica de la realitat o ho menystinguessin i continuessin pensat, en abstracte, en una entitat homogènia i uniforme anomenada Espanya. El nostre, és un país plutinacional i pluriregional. Per a alguns això pot semblar una complicació político-organitzativa innecessària, però no es pot negar que els instruments politics i científics per a abastar, analitzar o dirigir aquesta realitat són força menys complicats i rics que la mateixa tealitat. Ês aquesta la que al capdavail s'imposa. 


\section{LA PERSPECTIVA DE DEBAT I D'ESTUDI EN COMÚ}

En concloure les Jornades de Sitges vàrem adquirir el compromís de garantir la continuació del debat a través d'unes Segones Jornades. Però al marge d'aquest moment puntual, si bé extraordinàriament fecund, que poden ser unes Jornades d'estudi, potser l'opció que hauríem d'avaluar fóta que la Universitat s'acostumés a acollir sovint intercanvis més sistemàtics en la formació i en la recetca.

Caldria aconseguir uns quants objectius: trencar la ignorància mútua que es manté a la Universitat entre les nacions i regions d'Espanya, fer possible l'expansió de capacitats formatives i de recerca més enità de les pròpies "fronteres», configurar un coneixement més complet $i$ crític de la nostra realitat social. Tot plegat podria ser i caldria que fos fet, ja sigui mitjançant les disciplines institucionalitzades: economia, sociologia, històtia, geografia, etc.; ja sigui impulsant estudis i formació interdisciplinar.

Crec que podríem començar amb unes quantes experiències que, a tall d'exemple, podrien ser les següents:

1. Recerca comparada i conjunta sobre temes d'actualitat likgats a l'estructura econòmica, política, educativa... que gaudissin d'un mateix suport metodològic, compartit des de diferents universitats espanyoles.

2. Cursos o seminaris estables que servissin perquè a cada universitat, o si més no a les més importants, s'hi acollís l'explicació d'allò que genèticament anomenem l'estructura sòcio-econòmico-política de les regions i nacionalitats. En considerar aspectes especifics no hauríem de substituir, sinó més aviat de pressuposar, l'ensenyament de les disciplines en les quals la «variable regional» fos un element cabdal.

3. Des d'un punt de vista més instrumental, fóra útil crear a cada Universitat una secció de la biblioteca amb el títol d'«autonomies», en la qual es recollis tota la bibliografia de l'àrea de les ciències socials que servís per a un millor conejxement de regions i nacionalitats. Caldria fer-ho de manera exhaustiva per tal d'evitar que documents, materials i publicacions d'una determinada regió es desconeguin pràcticament fora dels seus límits — i això passa sovint, ara com ara.

4. Potser fóra estimulant la creació d'un Institut interuniversitari que endegués les àrees de recetca $i$ consolidés els fons documentals suara esmentats, fomentant a més l'extensió i l'intercanvi universitaris.

Pot ser que algunes d'aquestes expetiències no puguin reeixir; tant de bo deixin pas a d'altres de més fructíferes. De qualsevol manera, però, la 
«Papers»: Revista de Sociologia

Universitat i els universitaris no acomplizien el seu paper si renunciaven a aprofundir críticament el significat de la convivència dels diversos pobles a l'Espanya d'avui.

Nota: UItra les ponències i comunicacions presentades a Sitges, he d'esmentat, petquè m'ha estat de gran utilitat, l'article de Francisco J. Llera La estructura social del Pais Vasco. 